\title{
Agenesis and aplasia of uterine body
}

INSERM

\section{Source}

INSERM. (1999). Orphanet: an online rare disease and orphan drug data base. Agenesis and aplasia of uterine body. ORPHA:180142

A rare, non-syndromic, uterovaginal malformation characterized by underdevelopment of the uterus, rang ing from complete absence to the presence of bilateral rudimentary horns with or without a cavity. Patients usually present with primary amenorrhea, abdominal/pelvic pain and/or infertility. 